\title{
Antitumor Effects of Self-Assembling Peptide-Emodin in situ Hydrogels in vitro and in vivo
}

\author{
Weipeng $\mathrm{Wei}^{1-3, *}$ \\ Jianhua Tang ${ }^{4, *}$ \\ Hongfang $\mathrm{Li}^{1-3}$ \\ Yongsheng Huang ${ }^{5}$ \\ Chengchen Yin $^{1-3}$ \\ Dan $\mathrm{Li}^{6}$ \\ Fushan Tang (D) ${ }^{1-3}$
}

'Department of Clinical Pharmacy, Key Laboratory of Basic Pharmacology of Guizhou Province and School of Pharmacy, Zunyi Medical University, Zunyi 563000, People's Republic of China; ${ }^{2}$ Key Laboratory of Basic Pharmacology of Ministry of Education and Joint International Research Laboratory of Ethnomedicine of Ministry of Education, Zunyi Medical University, Zunyi 563000, People's

Republic of China; ${ }^{3}$ Key Laboratory of Clinical Pharmacy of Zunyi City, Zunyi Medical University, Zunyi 563000, People's Republic of China; ${ }^{4}$ Cancer Research UK Manchester Institute, The University of Manchester, Cheshire SKI0 4TG, UK; ${ }^{5}$ Peking Union Medical College, Chinese Academy of Medical Sciences, Institute of Basic Medical Sciences, Beijing 100005, People's Republic of China;

${ }^{6}$ State Key Laboratory of Molecular Oncology, National Cancer Center/National Clinical

Research Center for Cancer/Cancer Hospital, Chinese Academy of Medical Sciences and Peking Union Medical College, Beijing 10002I, People's Republic of China

*These authors contributed equally to this work

Correspondence: Fushan Tang

Department of Clinical Pharmacy, School of Pharmacy, Zunyi Medical University, Guizhou, People's Republic of China

Tel +8685I 28642337

Fax +8685I 28642334

Email fstang@vip.163.com

Dan Li

Cancer Hospital, Chinese Academy of Medical Sciences, Beijing, People's Republic of China Tel +8610 87787/07

Email eileenld@gmail.com
This article was published in the following Dove Press journal: International Journal of Nanomedicine

Purpose: To study the in vitro and in vivo antitumor effects of the colloidal suspension-in situ hydrogel of emodin (EM) constructed with the self-assembling peptide RADA16-I and systematically evaluate the feasibility of the delivery system.

Methods: The MTT and colony-formation assays were used to determine the viability of normal cells NCTC 1469 and tumor cells Hepa1-6. The uptake of EM in the RADA16-I-EM in situ hydrogel by tumor cells was analyzed by laser confocal microscope and flow cytometry. Flow cytometry was used to detect the cell apoptosis and cell cycle distribution. Transwell assay was used to detect the migration and invasion of tumor cells. The antitumor efficacy of the RADA16-I-EM in situ hydrogel and its toxic effects was further assessed in vivo on Hepa1-6 tumor-bearing C57 mice.

Results: The results showed that the RADA16-I-EM in situ hydrogels could obviously reduce the toxicity of EM to normal cells and the survival of tumor cells. The uptake of EM by the cells from the hydrogels was obviously increased and could significantly induce apoptosis and arrest cell cycle in the G2/M phase, and reduce the migration, invasion and clone-formation ability of the cells. The RADA16-I-EM in situ hydrogel could also effectively inhibit the tumor growth and obviously decrease the toxic effects of EM on normal tissues in vivo.

Conclusion: Our results demonstrated that RADA16-I has the potential to be a carrier for the hydrophobic drug EM and can effectively improve the delivery of hydrophobic antitumor drugs with enhanced antitumor effects and reduced toxic effects of the drugs on normal cells and tissues.

Keywords: self-assembling peptide, emodin, in situ hydrogels, antitumor, drug delivery system

\section{Introduction}

Tumors are malignant diseases that seriously affect human health, and chemotherapy is inevitably needed by most patients. ${ }^{1-3}$ Traditional chemotherapy often requires increased dosages and prolonged administration time to achieve the expected therapeutic effect, which will often increase drug toxicity and side effects. ${ }^{4}$ At present, the clinical use of most antitumor drugs is still challenged by the low bioavailability caused by poor water solubility and inability to accumulate at the tumor site. However, the poor selectivity of drugs and toxicity and side effects caused by the addition of corresponding excipients or solvents in the dosage form have limited the clinical use of many antitumor drugs to a certain extent. ${ }^{5-7}$ 
Emodin (EM) is a natural anthraquinone compound with promising antibacterial, blood microcirculation-promoting and antitumor effects. ${ }^{8-10}$ It was reported that EM can produce considerable toxicity to a variety of tumor cells. ${ }^{11-15}$ However, the poor solubility and ease of crystal precipitation of EM in water have resulted in difficulties associated with the injection administration. ${ }^{16,17}$ Most of the studies that examined novel drug delivery systems of EM, such as liposomes and nanoparticles, were unsuccessful because of low drug loading and cumbersome preparation processes of the dosage form. ${ }^{18,19}$

The injectable hydrogels can be used to effectively circumvent systemic side effects of traditional intravenous chemotherapy by locally releasing drugs at the tumor site. ${ }^{20,21}$ Based on different tumor types and stages, a variety of hydrogel drug delivery systems have been developed. ${ }^{22-27}$ Hydrogels are in an injectable solution, suspension or semi-solid state before administration and semi-solid or solid hydrogels can immediately form in situ at the site of drug administration through phase transition stimulated by external conditions (light, temperature, $\mathrm{pH}$, etc.). ${ }^{28-31}$ After the direct injection of the drug-loaded colloidal suspensions or solutions at the tumor site, the hydrogels can form in situ, and the drug loaded in the hydrogels can be mainly concentrated in the tumor tissue with improved therapeutic effects on tumors and reduced toxic effects of drugs on normal organs. ${ }^{32-38}$

Ionic complementary self-assembling peptides are structurally composed by alternately arranging positively and negatively charged amino acids with hydrophobic amino acids and can spontaneously assemble under the action of electrostatic forces and hydrophobic interactions. ${ }^{20,39}$ With the hydrophilic amino acids in the structure, including positively charged arginine (Arg, R) and negatively charged aspartic acid (Asp, D) at neutral $\mathrm{pH}$, and the hydrophobic amino acid as the non-polar amino acid alanine (Ala, A), the most typical ionic complementary self-assembling peptide, RADA16-I, has been believed and demonstrated that the hydrophobic regions of its high-level structure can encapsulate hydrophobic drugs, while the hydrophilic regions can maintain the stability of the system in aqueous solutions. ${ }^{40-43}$

We previously developed hydrophobic drug-loaded RADA16-I suspension-in situ hydrogels. ${ }^{44,45}$ In this study, the antitumor effects of EM-loaded RADA16-I suspensionin situ hydrogels were systematically evaluated in vitro and in vivo. A new hydrophobic drug administration form is expected to be developed by strengthening research on selfassembling peptides as drug carrier materials.

\section{Materials and Methods Materials}

Raw EM materials (batch no. FY1175S0310) with an EM purity $\geq 98 \%$ were purchased from Nantong Feiyu Biotechnology Co., Ltd. (Jiangsu, China). High-glucose Dulbecco's Modified Eagle's Medium (DMEM) and 1\% antibiotics $(100 \times$ streptomycin-penicillin) were purchased from HyClone Inc. (Logan, UT, USA). The 3-(4,5-dimethylthiazol-2-yl)-2,5-diphenyltetrazolium bromide (MTT) and phosphate-buffered saline (PBS) were purchased from Beijing Solarbio Technology Co., Ltd. (Beijing, China). Dimethyl sulfoxide (DMSO) was purchased from Beijing Dingguo Changsheng Biotechnology Co., Ltd. (Beijing, China). Foetal bovine serum (FBS) was purchased from Gibco (Thermo Fisher Scientific, Inc., Waltham, MA, USA). Trypsin-EDTA solution (0.25\%) was purchased from Biosharp Inc. (Shanghai, China). Heparin sodium (MFCD00081689) was purchased from Shanghai Yuanye Biological Technology Co., Ltd. (Shanghai, China). 4',6-Diamidino-2-phenylindole (DAPI) was purchased from Beijing Pulilai Gene Biotechnology Co., Ltd. (Beijing, China). Crystal violet was purchased from Shenyang Shengda Chemical Co., Ltd. (Shenyang, China). A BD Pharmingen ${ }^{\mathrm{TM}}$ cell cycle kit was purchased from BD Bioscience (Shanghai, China). An Annexin V-Alexa Fluor 647/PI apoptosis detection kit was purchased from Beijing Jinpulai Biotechnology Co., Ltd. (Beijing, China). PEG400 was purchased from Sinopharm Group Chemical Reagent Co., Ltd. (Beijing, China). Formaldehyde was purchased from Jiangsu Haixing Chemical Co., Ltd. (Jiangsu, China). Haematoxylin (BA-4097) and eosin (BA-4099) (H\&E) were purchased from Zhuhai Besso Biotechnology Co., Ltd. (Zhuhai, China). A TUNEL kit from Roche (30967400) was purchased from the Swiss Roche Group (Shanxi, China). The nuclear antigen Ki-67 was purchased from Wuxi Aurui Dongyuan Biotechnology Co., Ltd. (Wuxi, China). Male SPF-grade C57 mice weighing 18 20 g (experimental unit licence number: SYXK (Qian) 2014-003; experimental animal licence number: SCXK (Beijing) 2016-0002) were purchased from Speyford Biotechnology Co., Ltd. (Beijing, China). Animal experiments were conducted in accordance with the European Community guidelines (European Convention for the 
Protection of Spinal Cord Animals for Experimental and Other Scientific Purposes) and approved by the Institutional Animal Care and Use Committee of Zunyi Medical University (Approval number: ZMUER20142-069). NCTC 1469 normal mouse liver cells were purchased from Nanjing Saihongrui Biotechnology Co., Ltd. (Nanjing, China). Hepa1-6 mouse liver cancer cells were purchased from Shanghai Fuheng Biotechnology Co., Ltd. (Shanghai, China). Cell culture bottles and other related consumables were purchased from Corning, Inc. (Corning, NY, USA). All experimental protocols were performed in accordance with the relevant guidelines.

The self-assembling peptide RADA16-I (1712.77 g/ mol) was commercially synthesized by Shanghai Biotech Bioscience \& Technology Co., Ltd. (Shanghai, China). The peptide comprises the amino acid sequence n-RADARADARADARADA-c for RADA16-I. The $\mathrm{N}$-and C-termini of the peptides were protected by acetyl and amino groups, respectively.

\section{Cell Culture}

NCTC 1469 and Hepa1-6 cells were cultured in DMEM (Gibco) supplemented with 10\% FBS (Gibco), penicillin (100 U/mL), and streptomycin $(100 \mu \mathrm{g} / \mathrm{mL})$. The cells were incubated in a humidified atmosphere of $5 \% \mathrm{CO}_{2}$ at $37^{\circ} \mathrm{C}$.

\section{Analysis of Haemolytic Properties}

Haemoglobin was used as an indicator of haemolysis, that is, red blood cell damage. A haemolysis evaluation of the effects of non-drug-loaded RADA16-I was conducted, and the percentage of haemolysis was determined by comparison with a $100 \%$ haemolytic sample. Heparinized rabbit blood was collected, and a $2 \%$ erythrocyte suspension was prepared. The suspension was added to Eppendorf tubes, and RADA16-I samples at concentrations of 1.0, 3.0, 5.0, 7.0 , and $9.0 \mathrm{mg} / \mathrm{mL}$ were added to the tubes. PBS and $\mathrm{H}_{2}$ $\mathrm{O}$ were used as negative and positive controls, respectively. Then, the Eppendorf tubes were incubated in a $37^{\circ} \mathrm{C}$ constant temperature water bath for $3 \mathrm{~h}$. The tubes were then centrifuged at $3000 \mathrm{rpm} / \mathrm{min}$ for $5 \mathrm{~min}$. A full-wavelength scan of the positive control tube was measured using a UV-Vis spectrophotometer to determine the maximum absorption peak of haemoglobin. Supernatant absorption was then measured using the sample tubes at this wavelength. The percentage of haemolysis $(\% \mathrm{H})$ was calculated according to the following formula:

$$
\% \mathrm{H}=\left(\mathrm{D}_{1}-\mathrm{D}_{2}\right) /\left(\mathrm{D}_{3}-\mathrm{D}_{2}\right) \times 100 \%
$$

where $D_{1}$ is the average absorbance of the test sample, and $D_{2}$ and $D_{3}$ are the absorbances of the negative and positive controls, respectively.

\section{Investigation of Hydrogel Formation by a RADA I6-I-EM Suspension}

The self-assembling peptide RADA16-I-EM colloidal suspension was prepared by the magnetic stirring method, added into in vitro systems (PBS, $0.9 \% \mathrm{NaCl}$, or cell culture media) mimicking in vivo conditions, and injected para-tumorally or intra-tumorally to investigate the formation of hydrogels.

\section{Cell Viability Assay}

NCTC 1469 and Hepa1-6 cells were plated onto 96-well plates (4000 cells per well) in DMEM with 10\% FBS in the presence of RADA16-I $(0.5,1.0,2.0,4.0$, and $6.0 \mathrm{mg} /$ $\mathrm{mL}), \mathrm{EM}(60,80,100,120,140,160,180$, and $200 \mu \mathrm{M})$, or RADA16-I-EM hydrogels (in which the concentration of RADA16-I was $5.0 \mathrm{mg} / \mathrm{mL}$, and concentrations of EM were $60,80,100,120,140,160,180$, and $200 \mu \mathrm{M})$. DMEM served as the blank, and untreated cells served as controls. Cells were incubated for 24 and $72 \mathrm{~h}$ at $37^{\circ} \mathrm{C}$ with $5 \% \mathrm{CO}_{2}$. An MTT solution was prepared at $5 \mathrm{mg} / \mathrm{mL}$ in PBS and filtered through a $0.2-\mu \mathrm{m}$ filter. MTT $(20 \mu \mathrm{L} /$ well) was added to each well. Cells were further incubated with MTT at $37^{\circ} \mathrm{C}$ for $4 \mathrm{~h}$. Then, the spent medium was discarded, DMSO (150 $\mu \mathrm{L} /$ well) was added to each well, and the plate was further shaken for $10 \mathrm{~min}$ at room temperature. Finally, the absorbance of each well was measured at $490 \mathrm{~nm}$ using a microplate reader (Bio-Rad Laboratories, Hercules, CA, USA) to determine the OD values. The cell viability was calculated using the following calculation:

Cell survival rate $(\%)=\left(\mathrm{OD}_{1}-\mathrm{OD}_{2}\right) /\left(\mathrm{OD}_{3}-\mathrm{OD}_{2}\right)$ $\times 100 \%$

where $\mathrm{OD}_{1}$ is the absorbance of the sample, $\mathrm{OD}_{2}$ is the absorbance of the blank, and $\mathrm{OD}_{3}$ is the absorbance of the control.

\section{In vitro Fluorescence Imaging}

Cellular uptake of free EM and RADA16-I-EM hydrogels was evaluated by imaging the cells under a confocal laser scanning microscope (Leica, Wetzlar, Germany). The procedure used for the preparation of the cell samples was as follows. Hepa1-6 cells were cultured in DMEM on a special Petri dish for laser confocal microscopy at 
a suitable concentration of cells per dish. After growth overnight, the cells were treated with free EM and RADA16-I-EM hydrogels (in which the concentration of RADA16-I was $5.0 \mathrm{mg} / \mathrm{mL}$, and the final concentrations of EM were 120, 160, and $200 \mu \mathrm{M}$ ) and incubated for 24 $\mathrm{h}$. The culture medium was discarded, and the cells were washed with PBS and then fixed for $30 \mathrm{~min}$ in $4 \%$ paraformaldehyde. The fixed cells were then washed with PBS three times to remove excess paraformaldehyde, and their nuclei were stained with DAPI.

\section{Cellular Uptake of EM via Flow Cytometry}

Cellular uptake of EM from free EM and RADA16-I-EM hydrogels was also studied by flow cytometry (BectonDickinson, San Jose, CA, USA). The procedure used to prepare the cell samples was as follows. Hepa1-6 cells were cultured in DMEM on a 6-well plate at a suitable concentration of cells per well. After growth overnight, the cells were treated with free EM and RADA16-I-EM hydrogels (in which the concentration of RADA16-I was $5.0 \mathrm{mg} / \mathrm{mL}$ and the concentrations of EM were 120, 160, and $200 \mu \mathrm{M}$ ) and incubated for $24 \mathrm{~h}$. The culture medium was discarded, and the cells were washed with ice-cold PBS followed by the addition of trypsin to detach the cells from the plate; then, the cells were re-suspended in $300 \mu \mathrm{L}$ of PBS to obtain single cells.

\section{Annexin V/PI Staining Assay for Apoptosis}

A cell apoptosis study was performed with Hepa1-6 cells using an Annexin V-Alexa Fluor 647/PI double staining assay kit supplied by BD Biosciences, China. In brief, cells were cultured $\left(60-\mathrm{mm}\right.$ dish at $\left.37^{\circ} \mathrm{C}\right)$ and then treated separately with free EM and RADA16-I-EM hydrogels (in which the concentration of RADA16-I was $5.0 \mathrm{mg} / \mathrm{mL}$, and the concentrations of EM were 120,160, and $200 \mu \mathrm{M}$ ) for $24 \mathrm{~h}$. The cells were then collected and washed with ice-cold PBS, stained with Annexin V-Alexa Fluor 647 and PI for $15 \mathrm{~min}$ at room temperature in the dark according to the manufacturer's protocol, and analysed by using flow cytometry (Becton-Dickinson, San Jose, CA, USA) to examine the apoptotic cell numbers.

\section{Cell Cycle Detection Assay}

Hepa1-6 cells were seeded in six-well plates. After incubation for $24 \mathrm{~h}$, the cells were treated with free EM and RADA16-I-EM hydrogels (in which the concentration of
RADA16-I was $5.0 \mathrm{mg} / \mathrm{mL}$ and the concentrations of EM were 120,160 , and $200 \mu \mathrm{M}$ ) for $24 \mathrm{~h}$ in complete medium. The cells were then collected by trypsinization and washed with ice-cold PBS. The cells were fixed with ice-cold $75 \%$ ethanol $(\mathrm{v} / \mathrm{v})$ overnight at $-20^{\circ} \mathrm{C}$; the samples were then centrifuged, washed with ice-cold PBS, and stained with propidium iodide (PI, $50 \mu \mathrm{g} / \mathrm{mL}$ ) for $30 \mathrm{~min}$ at $37^{\circ} \mathrm{C}$ in the dark according to the manufacturer's instructions. Finally, the samples were analysed by flow cytometry (BectonDickinson, San Jose, CA, USA), and the percentage of cell cycle cells was calculated according to the number of cells in the respective phase.

\section{Invasion and Migration Assays}

Migration and invasion studies were conducted using a Transwell plate that was coated with (for invasion) or without (for migration) Matrigel matrix (BD Biosciences, Bedford, MA). Hepa1-6 cells were cultured (60-mm dish at $37^{\circ} \mathrm{C}$ ) and then treated separately with free EM and RADA16-I-EM hydrogels (in which the concentration of RADA16-I was $5.0 \mathrm{mg} / \mathrm{mL}$, and the concentrations of EM were 120,160 , and $200 \mu \mathrm{M}$ ) for $24 \mathrm{~h}$. The cells were then collected and washed with PBS. After preparing cell suspensions in serum-free DMEM containing $1 \times 10^{5}$ cells, the cells were then seeded into the upper chamber, and 700 $\mu \mathrm{L}$ DMEM with $20 \%$ FBS was added to each well under the chambers. After culturing for $18 \mathrm{~h}$ at $37^{\circ} \mathrm{C}$ and $5 \%$ $\mathrm{CO}_{2}$, cells that migrated or invaded through the membrane were fixed with methanol for $15 \mathrm{~min}$ and then stained with a $2.0 \%$ crystal violet-methanol solution for $15 \mathrm{~min}$. Finally, invasive and migrated cell numbers were visualized by fluorescence microscopy and counted.

\section{Colony-Formation Assay}

For the colony-formation assay, Hepa1-6 cells were cultured $\left(60-\mathrm{mm}\right.$ dish at $\left.37^{\circ} \mathrm{C}\right)$ and then treated separately with free EM and RADA16-I-EM hydrogels (in which the concentration of RADA16-I was $5.0 \mathrm{mg} / \mathrm{mL}$, and the concentrations of EM were 120, 160, and $200 \mu \mathrm{M}$ ) for 24 h. The cells were collected and washed with PBS. Cells were seeded in six-well plates at a concentration of 800 cells per well containing DMEM with $10 \%$ FBS, and the culture medium was replaced with a complete medium every $72 \mathrm{~h}$. The cells were incubated at $37^{\circ} \mathrm{C}$ and $5 \%$ $\mathrm{CO}_{2}$ for 8 days. After 8 days, the cells were washed with PBS, fixed with methanol for $15 \mathrm{~min}$, and stained with a $2.0 \%$ crystal violet-methanol solution for $15 \mathrm{~min}$. The six-well plates were washed with water and dried at room 
temperature. The colonies were visualized using a gel imager and counted.

\section{In vivo Antitumor Efficacy and Immunohistology}

For the in vivo therapeutic efficacy of the RADA16-I-EM hydrogel, C57 mice bearing Hepa1-6 cells were randomly divided into four groups ( $\mathrm{n}=8$ per group) when the tumors reached a size of approximately $150-250 \mathrm{~mm}^{3}$. PBS served as a negative control. The experimental groups included non-drug-loaded RADA16-I hydrogel, free EM (10.0 mg/ $\mathrm{kg}$ per dose), and RADA16-I-EM hydrogels (at an equivalent dose of $10.0 \mathrm{mg} / \mathrm{kg}$ EM per dose). The animals were injected with $50 \mu \mathrm{L}$ of the control or experimental group dose via intra-tumor injection every 2 days. The tumor diameters $(\mathrm{mm})$ and body weight $(\mathrm{g})$ were monitored before each dosing regimen seven times for a total of 14 days. The mice were sacrificed by cervical vertebral dislocation after 14 days, and their tumor tissues were dissected and weighed, and fixed in a $10 \%$ formaldehyde solution. The lungs, heart, kidneys, liver, and spleen were also collected and fixed in a $10 \%$ formaldehyde solution. In the histological assay, tumor and organ tissues were fixed with a $10 \%$ formaldehyde solution for $48 \mathrm{~h}$ at $4^{\circ} \mathrm{C}$, and tissue sections were stained with H\&E for microscopic observation. Apoptosis of cells in tumor tissues following treatments was evaluated using the TUNEL assay according to the manufacturer's instructions. For analysis of cell proliferation, Ki-67 immunohistochemical staining was applied according to the manufacturer's instructions. The tumor volumes were measured by the following formula:

Tumor volume $(\mathrm{V})=(\text { tumor width })^{2} \times$ tumor length $/ 2$

\section{Statistical Analysis}

Statistical analysis was performed using SPSS 18.0 statistical software. All the obtained data are presented as the mean $\pm \mathrm{SD}$. Comparison between two groups was statistically evaluated by Student's $t$-test; multiple comparisons were statistically evaluated by the one-way ANOVA with the LSD-t or the Dunnett-t-test. A probability (P) less than 0.05 was considered statistically significant.

\section{Results and Discussion}

\section{In vitro Haemocompatibility and}

\section{Cytocompatibility of RADAI6-I}

Haemocompatibility and cytocompatibility are two important factors considering biomaterial applications. ${ }^{46,47}$ The results of the haemolysis experiment showed that the $2.0 \%$ erythrocyte suspension was completely ruptured in $\mathrm{H}_{2}$ $\mathrm{O}$ (the hypotonic solution), but haemolysis did not occur in PBS (the isotonic solution) or the RADA16-I solution (Figure 1A i ). A full-wavelength scan of the positive control supernatant $\left(\mathrm{H}_{2} \mathrm{O}\right)$ showed that haemoglobin had
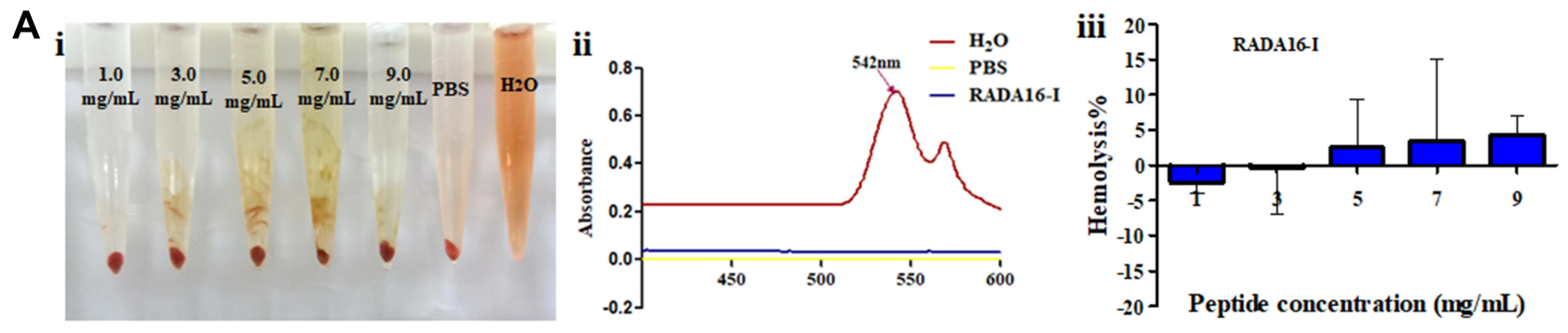

Wavelength(nm)
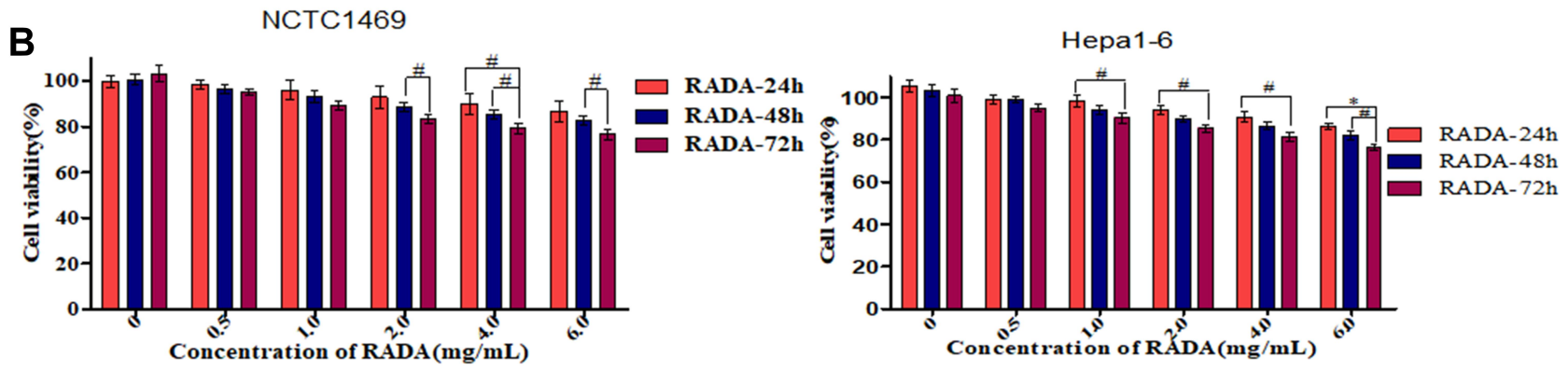

Figure I (A) Hemolytic activity of self-assembling peptide RADAI6-I evaluated using rabbit red blood cells after $3 \mathrm{~h}$ of incubation. (i) Hemolysis of red blood cells in RADA I6-I water solution, PBS and pure water; (ii) Full-wavelength scanning of positive control tube $\mathrm{H}_{2} \mathrm{O}$ and PBS, RADAI6-I solutions; (iii) Statistical analysis of hemolysis rate of RADA I6-I solutions. (B) Cellular toxicity of RADAI6-I. Data were calculated from three independent experiments. ${ }^{\#} P<0.05,{ }^{*} P<0.0$ I. 


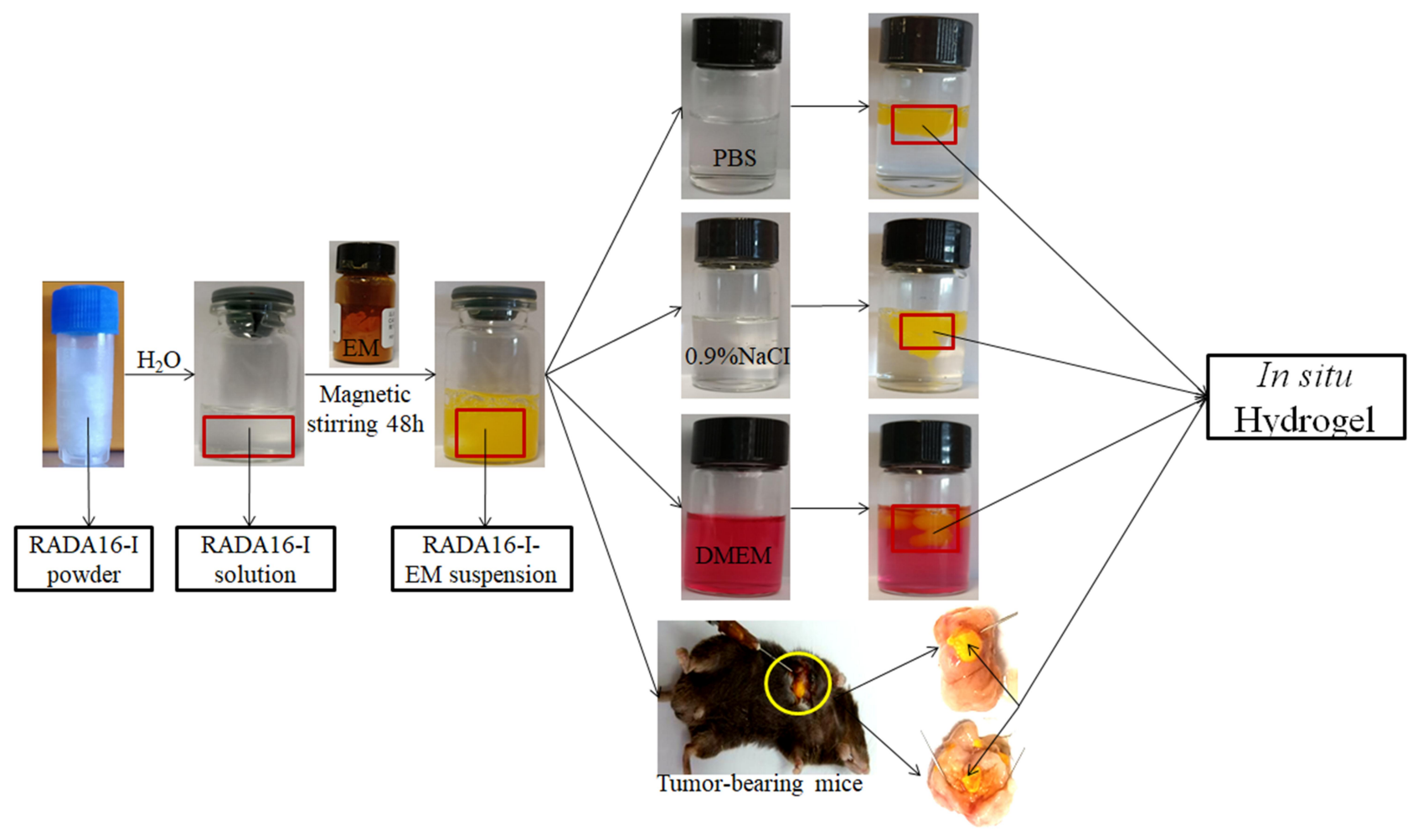

Figure 2 Formation of RADA I6-I-EM suspension-in situ hydrogel system.

a maximum absorption peak at $542 \mathrm{~nm}$, while neither the PBS nor RADA16-I solutions had absorption peaks at this wavelength (Figure 1A ii). The supernatant of each experimental group containing a peptide solution was tested for absorbance at $542 \mathrm{~nm}$; the calculated RADA16-I concentration was $1.0-9.0 \mathrm{mg} / \mathrm{mL}$, and the haemolysis rate was less than $5.0 \%$ (Figure 1Aiii). According to previous reports, materials with a haemolysis rate of less than $5 \%$ are considered safe materials meeting the requirements of biomaterials and medical devices for haemolysis experiments. ${ }^{48,49}$ Taken together, RADA16-I has good blood compatibility in this concentration range.

The cytotoxicity of RADA16-I on cells (Hepa1-6 and NCTC 1469) was detected using the MTT assay to evaluate the cell compatibility of RADA16-I. The cytotoxicity results showed that with the increasing RADA16-I concentration and incubation time, the inhibitory effects of RADA16-I on the proliferation of cancer cells and normal cells were not significant, and the final cell viabilities were both greater than $80 \%$ (Figure $1 \mathrm{~B}$ ), which was indicative of the zero-grade and I-grade ranges according to the

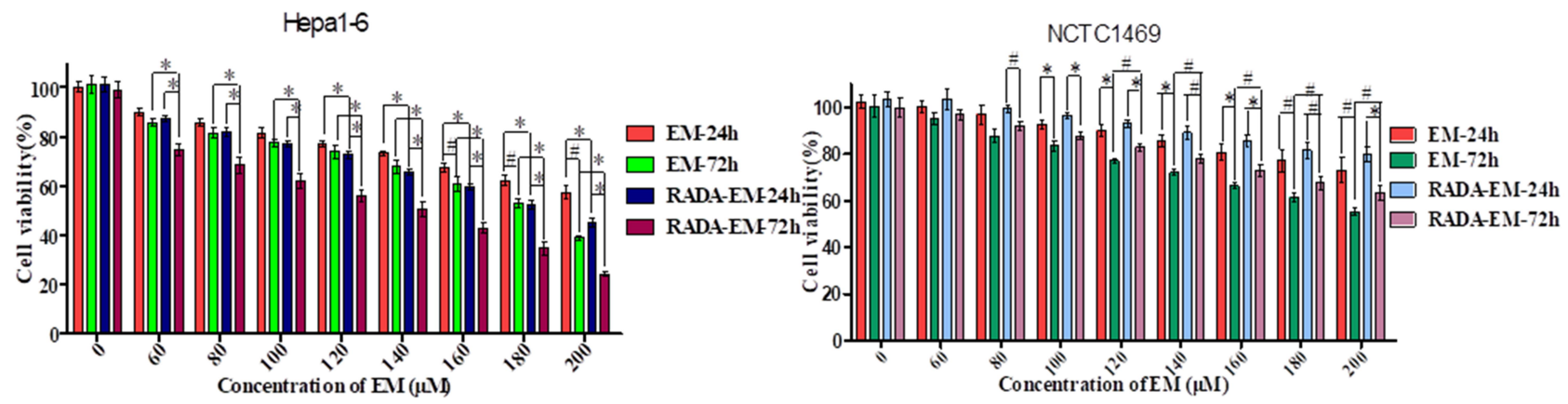

Figure 3 Inhibition effects of free EM (water suspension), RADAI6-I-EM in situ hydrogels incubated 24 and 72 hours on proliferation of cells. [RADAI6-I] =5 mg/mL; Data were calculated from three independent experiments. ${ }^{\#} P<0.05, * P<0.01$.

Abbreviations: RADA, self-assembling RADAI6-I peptide; EM, emodin. 
cytotoxicity evaluation standard, therefore meeting the cytotoxicity requirements of the pharmacopoeia evaluation of biological materials. The above experimental results preliminarily showed that the self-assembling peptide RADA16-I hydrogel is biologically safe and has the potential to be a drug delivery carrier.

\section{Hydrogel Formation of the RADA I6-I-EM Suspension}

As shown in Figure 2, the results of the hydrogel formation showed that the RADA16-I-EM colloidal suspension can immediately form three-dimensional hydrogels in situ, in buffer solutions in vitro, and in para-/intra-tumor tissues in vivo, and the hydrogels were resistant to dispersal to some extent.

\section{In vitro Cell Viabilities}

EM and its derivatives possess anticancer activity against various tumors, including liver and lung tumors. ${ }^{12,13}$ Here, the antitumor efficiency of the RADA16-I-EM suspension was evaluated using the MTT assay and Hepa1-6 liver cancer cells. The toxic effects of EM on normal cells (NCTC 1469) were also analysed by the MTT assay after the drug was encapsulated in RADA16-I. The EM in water suspension (free EM) and RADA16-I-EM hydrogels both obviously inhibited the proliferation of Hepa1-6 cells within 24-72 h. With the increase of the incubation time and dose, the antiproliferative effects of free EM and RADA16-I-EM hydrogels on Hepa1-6 cells increased notably, but the antiproliferative effects of RADA16-I-EM hydrogels were significantly greater than that of the free EM, particularly after $72 \mathrm{~h}$ of incubation $(P<0.05$, Figure 3$)$. For NCTC 1469 cells, both free EM and RADA16-I-EM hydrogels had certain inhibitory effects on proliferation; however, the inhibitory effect of RADA16-I-EM hydrogels on normal cells was significantly less than that of free EM $(P<0.05$, Figure 3$)$. This phenomenon may be related to the slow release of EM into the cells, controlled by RADA16-I-EM hydrogels that formed in situ, resulting in an inability to immediately reach the minimum toxic concentration of the drug, thus causing less damage to normal cells. It was concluded that the selfassembling peptide RADA16-I can effectively control the
A
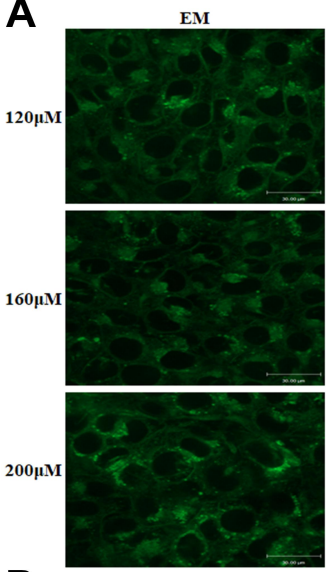

B

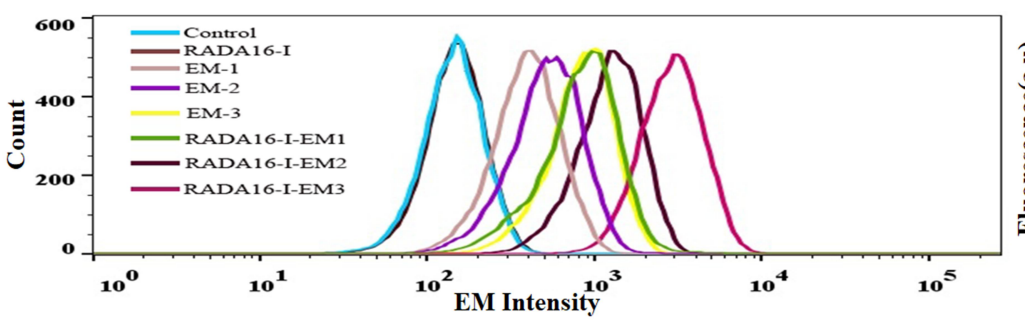

RADA16-I-EM
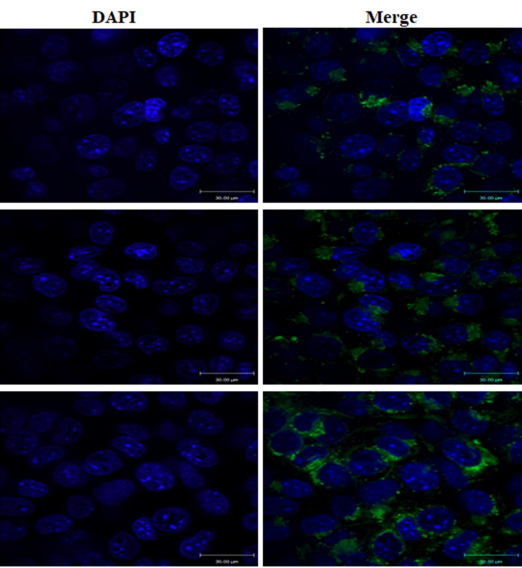
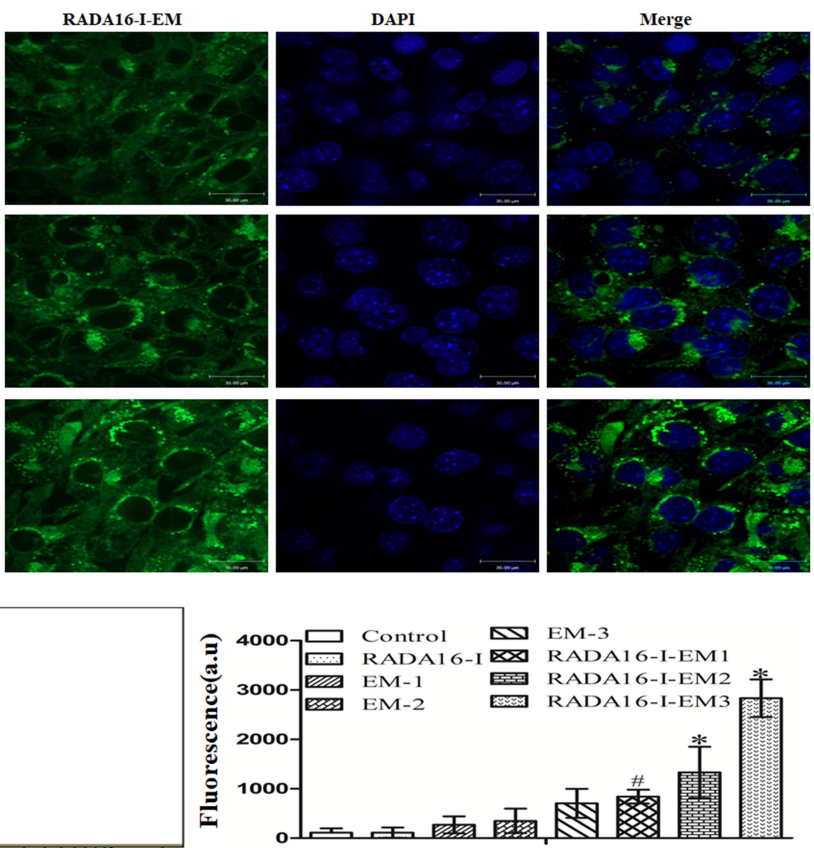

Figure 4 (A) Confocal images of Hepa I-6 cells incubated with free EM (water suspension) and RADA I6-I-EM hydrogels at 24 h. Blue and green colors represent DAPI and $E M$, respectively; Scale bars are $30 \mu \mathrm{m}$. [EM] $=120,160,200 \mu \mathrm{M}$. (B) Flow cytometry of uptake EM (left) and quantification (right) after $24 \mathrm{~h}$ incubation. The data were presented as the mean $\pm S D, n=3$. I, 2 and 3 represent EM concentrations of I20, I60, $200 \mu M$, respectively, [RADAI6-I] $=5 \mathrm{mg} / \mathrm{mL},{ }^{\#} P<0.05,{ }^{*} P<0.0 \mathrm{I}$ vs free EM. 

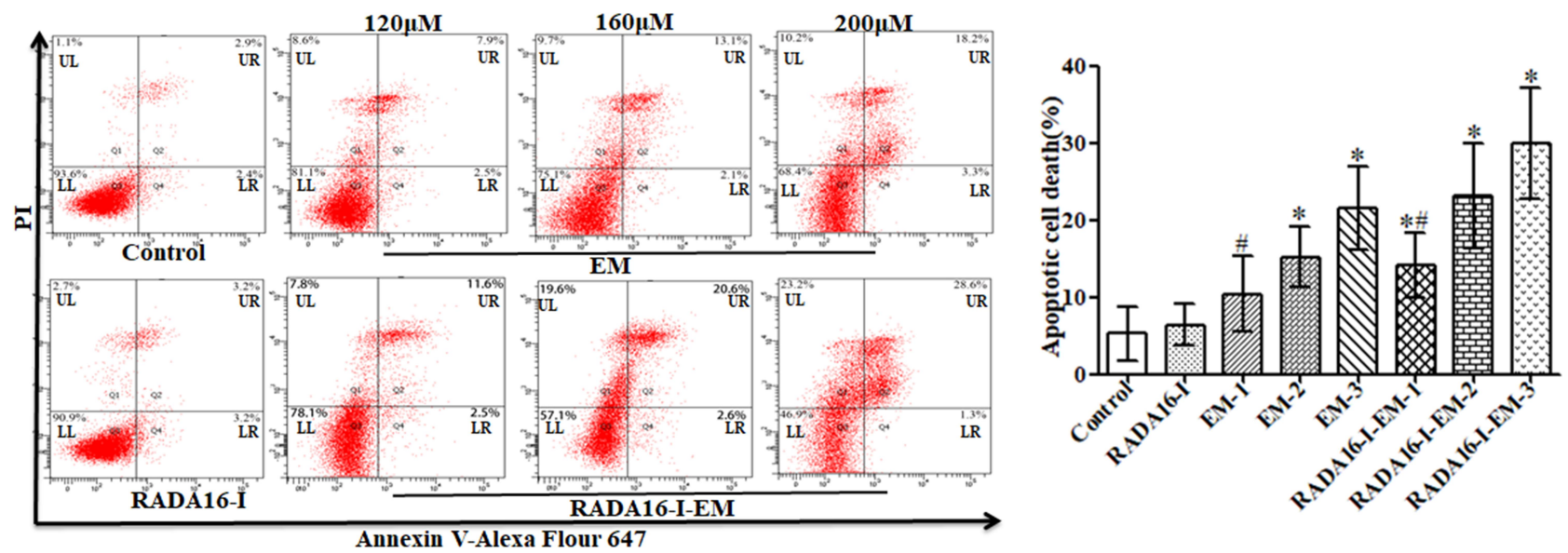

Figure 5 Flow cytometry results for cancer cells. Percentage of apoptosis cells $\left(Q_{2}+Q_{4}\right)$ were compared among groups. The data were presented as the mean $\pm S D, n=3$. I, 2 and 3 represent EM concentrations of $120,160,200 \mu \mathrm{M}$, respectively, [RADAI6-I] $=5 \mathrm{mg} / \mathrm{mL},{ }^{\#} P<0.05$, ${ }^{*} P<0.01$ vs free EM or the control.

Abbreviations: LL, living cells; LR, early apoptotic cells; UL, necrotic cells; UR, late apoptotic cells.

release of EM, prolong the inhibitory effect of EM on the growth of Hepa1-6 liver cancer cells in vitro, and reduce the toxic effect of EM on normal cells.

\section{In vitro Cellular Uptake}

Whether the encapsulated drugs are successfully released and taken up by cells is the key point for evaluating drugloaded nanogels and their chemotherapeutic agents. ${ }^{50,51}$ In this study, laser confocal microscopy and flow cytometry were employed to explore the cellular uptake of nanoparticles. As shown in Figure 4A, after the cells were incubated for $24 \mathrm{~h}$ with the drugs, the cytoplasmic distribution of the green fluorescence of EM in cells of the RADA16-I-EM in situ hydrogels group was significantly greater than that of free EM. The results of quantitative detection by flow cytometry showed similar results. As shown in Figure 4B, as the concentration of EM increased, the amount of EM detected in the cells also increased, but the amount of EM entering the cells from the RADA16-I-EM in situ hydrogels was significantly greater than that from the free EM $(P<0.01)$. The cellular uptake of EM from RADA16-I-EM in situ hydrogels dramatically increased compared with that from the free EM. Considering that the main difference between free EM and RADA16-I-EM was the introduction of RADA16-I in the EM suspension (RADA16-I-EM), it is reasonable to speculate that RADA16-I plays an important role in the improvement of the solubility of hydrophobic drugs as well as their anticancer performance.

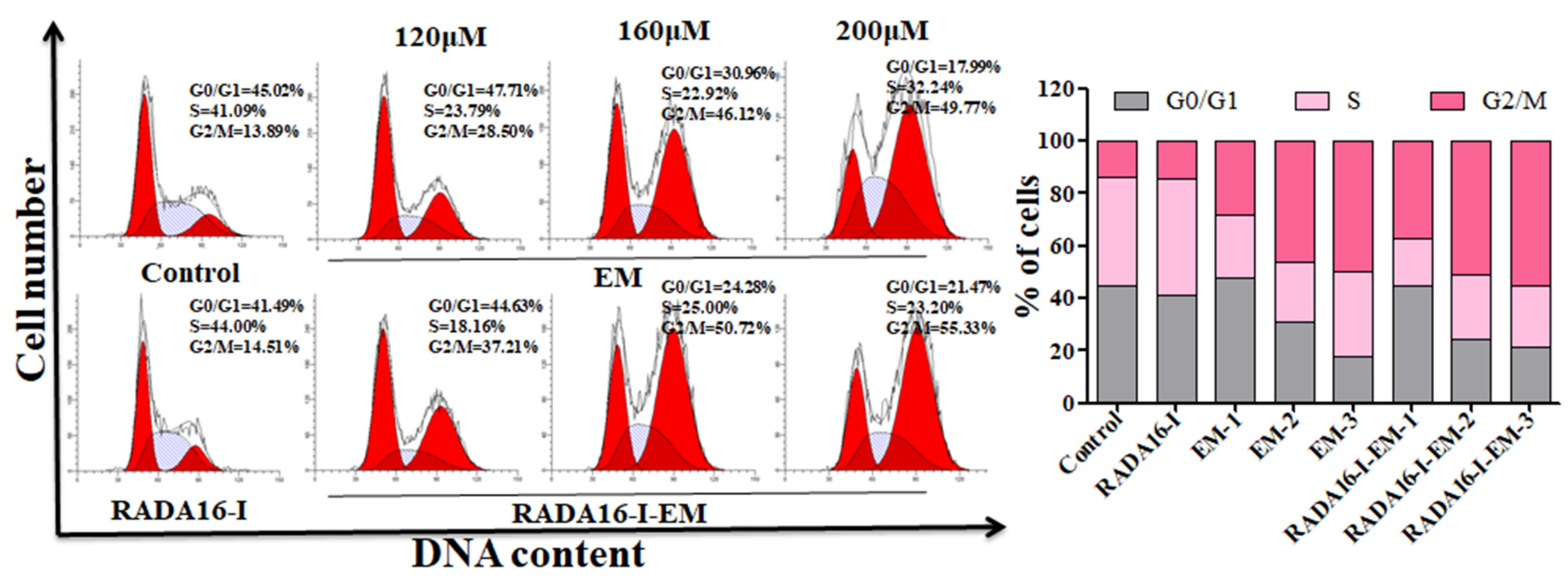

Figure 6 Hepal-6 cells incubated with free EM (water suspension) or RADAI6-I-EM hydrogels for $24 \mathrm{~h}$ and the cell cycles analyzed under flow cytometry. The percentage of G0/GI, S and G2/M phase distributions of free EM or RADAI6-I-EM hydrogels treated cells was measured by ModFit. LT 3.3 software. I, 2 and 3 represent EM concentrations of I20, 160, $200 \mu \mathrm{M}$, respectively, [RADAI6-I] $=5 \mathrm{mg} / \mathrm{mL}$. 


\section{Evaluation of Cell Apoptosis}

It has been cumulatively documented that EM causes cell growth inhibition via an apoptotic mechanism. ${ }^{52,53}$ In the current work, Hepa1-6 cells were employed to investigate the apoptotic process caused by free EM and RADA16-I-EM hydrogels. As shown in Figure 5, untreated Hepa1-6 cells showed little apoptosis and necrosis (early apoptosis: $\sim 2.4 \%$, late apoptosis: $\sim 2.9 \%$, and necrosis: $\sim 1.1 \%$ ); when the final concentration of EM reached $200 \mu \mathrm{M}$, free EM led to increases in both cellular apoptosis and necrosis: $\sim 3.3 \%$ early apoptosis, $\sim 18.2 \%$ late apoptosis, and $\sim 10.2 \%$ necrosis. The death of cells treated with RADA16-I-EM hydrogels changed dramatically with $\sim 1.3 \%$ early apoptosis, $\sim 28.6 \%$ late apoptosis and $\sim 23.2 \%$ necrosis. Compared with the blank control, RADA16-I hydrogels without EM had little effect on early apoptosis, late apoptosis or necrosis in cells. The results clearly showed that EM loaded in RADA16-I assembly produced a superior anticancer effect to that of EM alone through the enhanced induction of cancer cell apoptosis.

\section{Examination of Cell Cycle Distribution}

To further investigate the mechanism underlying EMinduced tumor cell proliferation inhibition, we analysed the effect of free EM and RADA16-I-EM hydrogels on cell cycle distribution by flow cytometry. As shown in Figure 6, compared with untreated Hepa1-6 cells, an accumulation of cells in the $\mathrm{G} 2 / \mathrm{M}$ phase from $\sim 13.89 \%$ to $\sim 49.77 \%$ was observed when Hepa1-6 cells were treated with a final EM concentration of $200 \mu \mathrm{M}$. Simultaneously, the cell fractions in the $\mathrm{S}$ and $\mathrm{G} 0 / \mathrm{G} 1$ phases decreased from $\sim 41.09 \%$ and $\sim 45.02 \%$ to $\sim 32.24 \%$ and $\sim 17.99 \%$, respectively. In addition, compared with free EM,
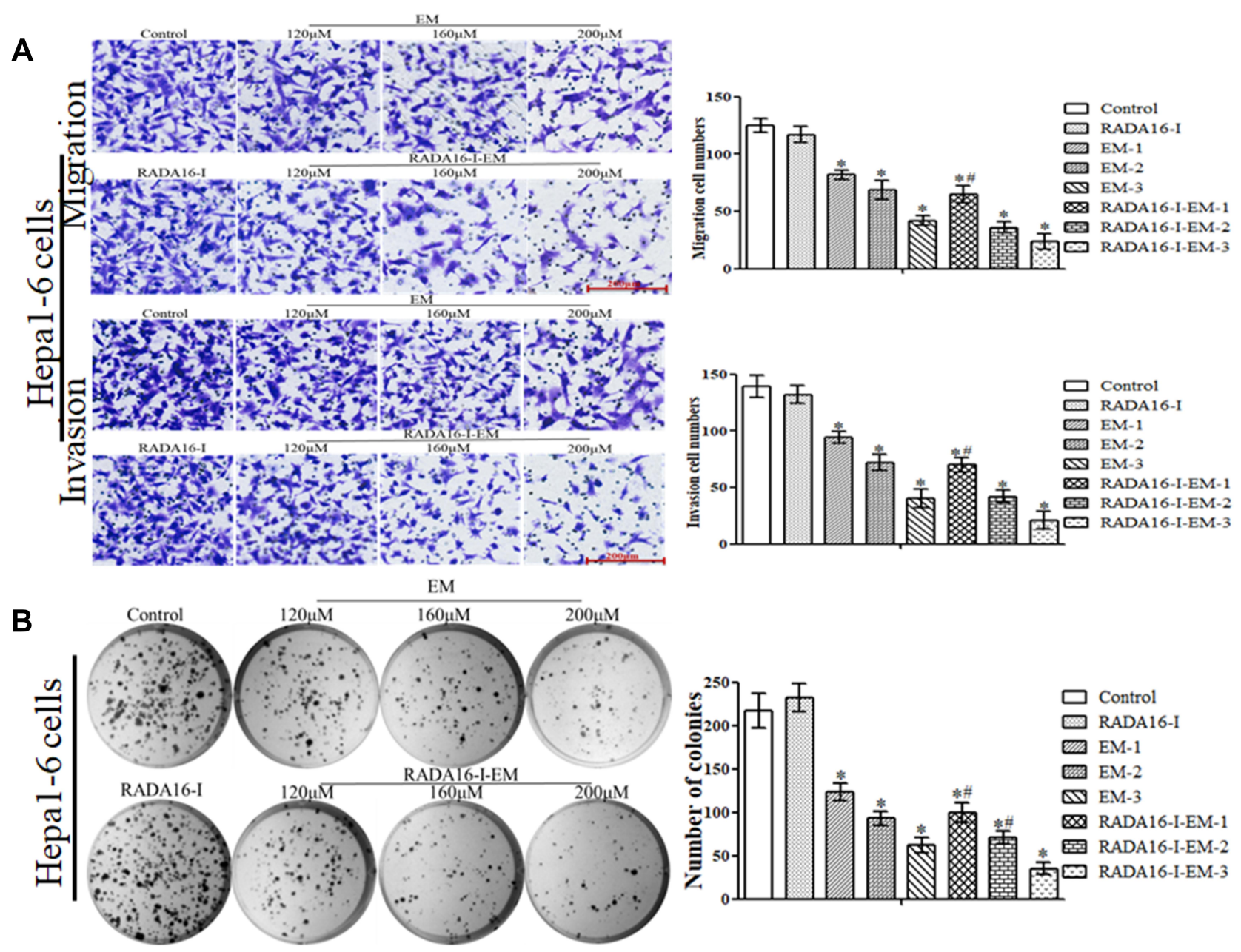

Figure 7 (A) Representative results of Transwell migration/invasion assays and corresponding quantification in Hepal-6 cells after treatment with free EM (water suspension) or RADAI6-I-EM hydrogels for $24 \mathrm{~h}$ (Scale bar $=200 \mu \mathrm{m}$ ). (B) The colony-formation results of Hepal-6 cells after treatments of free EM and RADAI6I-EM hydrogels for $24 \mathrm{~h}$ were exhibited. I, 2 and 3 represent EM concentrations of I20, I60, $200 \mu \mathrm{M}$, respectively. [RADAI6-I] $=5 \mathrm{mg} / \mathrm{mL}$. Data are presented as mean \pm SD of three independent experiments conducted in duplicate, ${ }^{\#} P<0.05 ;{ }^{*} P<0.01$ vs EM or Control group. 


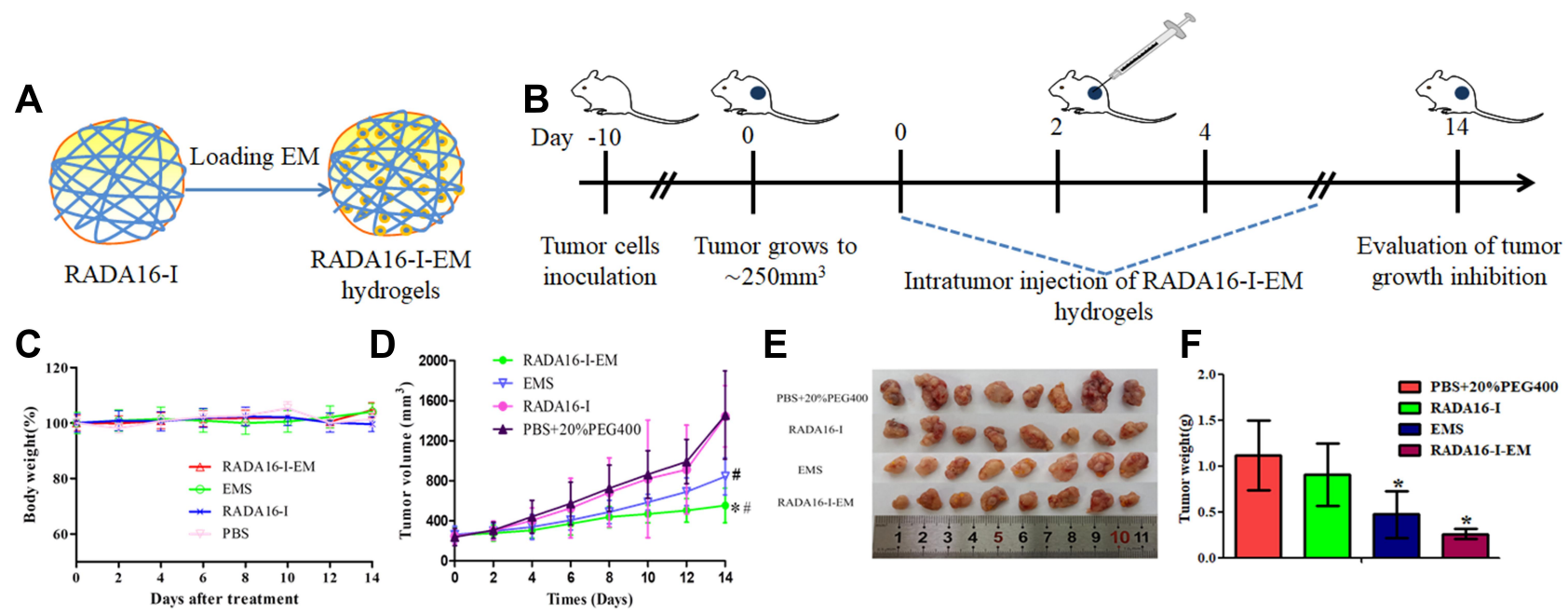

Figure 8 In vivo therapeutic efficiency of C57 mice with Hepal-6 xenograft model was treated with RADAI6-I, EMS or RADAI6-I-EM. (A) Illustration of RADAI6-I encapsulated EM. (B) Illustration of RADA I6-I/EMS/RADAI6-I-EM for the intra-tumor administration of tumor-bearing mice. (C) Body weight change in various groups. (D) Tumor volume change in various groups. (E) The images of dissected tumor tissues. (F) Tumor weight was recorded after the last injection. ${ }^{* P}<0.01$ vs $P B S ;{ }^{\#}<0.05$ vs EMS or PBS. Data are presented as mean \pm SD $(n=8)$.

Abbreviation: EMS, emodin water suspension.

RADA16-I-EM hydrogels led to significant cell cycle arrest, in which the cell accumulation of the G2/M phase increased from $\sim 14.51 \%$ to $\sim 55.33 \%$, and the cell fraction of the $\mathrm{S}$ and $\mathrm{G} 0 / \mathrm{G} 1$ phases dramatically decreased from $\sim 44.00 \%$ and $\sim 41.49 \%$ to $\sim 23.20 \%$ and $\sim 21.47 \%$, respectively. Taken together, it was demonstrated that EM induces $\mathrm{G} 2 / \mathrm{M}$ arrest in liver cancer cells and that RADA16-I-EM in situ hydrogels block G2/M phase arrest more significantly than EM alone.

\section{In vitro Cell Migration, Invasion, and Cloning Capabilities}

The Transwell and clone-formation assays were applied to elucidate the effects of EM in the free EM and the RADA16-I-EM in situ hydrogels on the migration, invasion, and proliferation of Hepa1-6 cells. The cells in RADA16-I-EM in situ hydrogel group showed lower levels of membrane penetration and clone formation than those in the free EM group. Using the Transwell system, we verified that RADA16-I-EM in situ hydrogels reduced the migration and invasion ability of Hepa1-6 cells. As shown in Figure 7A, both free EM and RADA16-I-EM in situ hydrogels effectively inhibited the migration and invasion of Hepa1-6 cells compared with untreated cells and cells treated with empty vector RADA16-I. In addition, RADA16-I-EM in situ hydrogels had stronger inhibition effects on cell migration and invasion than free EM. The clone-formation assays revealed that free EM and RADA16-I-EM in situ hydrogels attenuated the colony-forming ability of Hepa1-6 cells compared with untreated cells and cells treated with empty vector RADA16-I (Figure 7B), while RADA16-I-EM in situ hydrogels reduced the colonyforming ability of Hepa1-6 cells more significantly than free EM. Based on the migration, invasion and proliferation assays, we concluded that the self-assembling peptide RADA16-I can stabilize the EM in aqueous solutions and achieve a slow-release effect, which can increase the cellular uptake of EM from the RADA16-I-EM in situ hydrogels by tumor cells to inhibit the migration, invasion and cloning formation of tumor cells more significantly, thereby enhancing the antitumor effects of EM on tumor cells.

\section{In vivo Studies in Hepa I-6 Tumor-Bearing Mice}

To further investigate the potential of RADA16-I-EM in situ hydrogels for cancer treatment in vivo, Hepa1-6 tumor-bearing mouse models were treated with free EM and RADA16-I-EM hydrogels via intra-tumor injection (Figure 8A and B). As shown in Figure 8C, the weight of mice in each group did not change significantly after 14 days of administration. The tumors in mice treated with PBS and RADA16-I grew rapidly, but tumor growth in 

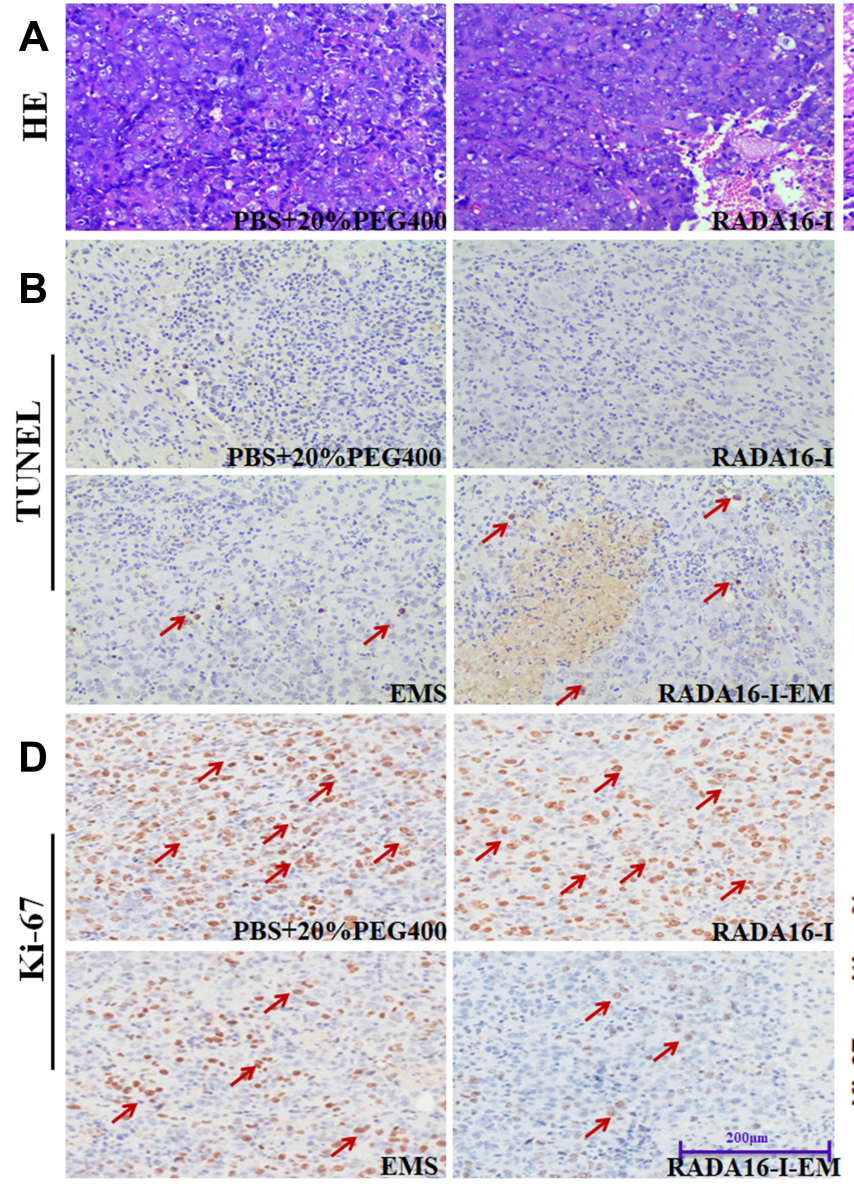

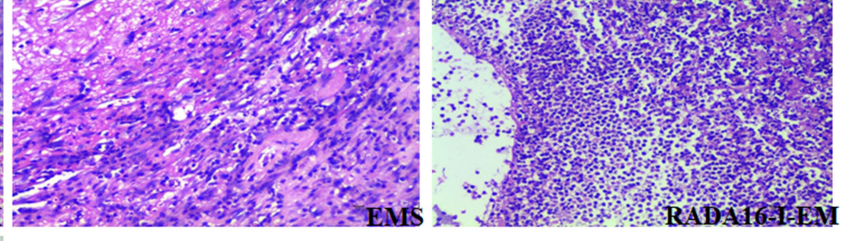

C

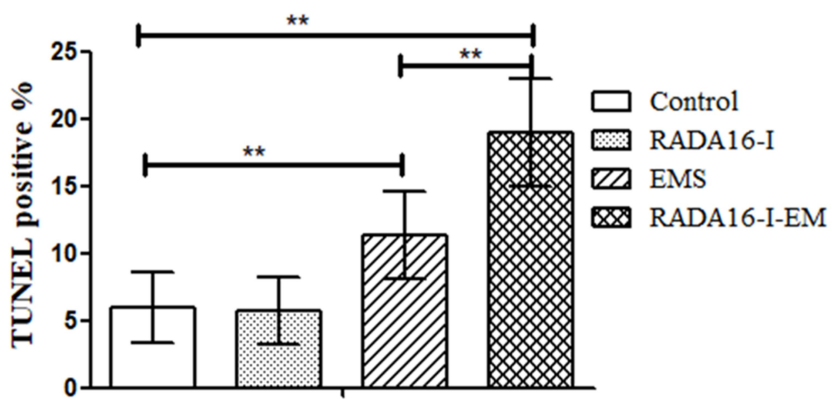

E

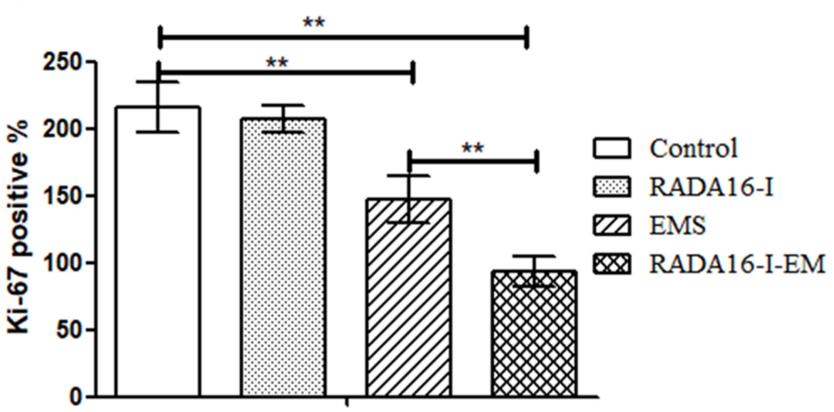

Figure 9 Anti-tumor activity in xenograft models in vivo. (A) H\&E, (B) TUNEL and (D) Ki-67 staining on tumor sections collected from Hepa l-6 tumor-bearing mice after various treatments, ( $C$ and $\mathbf{E}$ ) represent the expression of TUNEL-positive cells and Ki67-positive cells, respectively. Data are expressed as the mean \pm SD, $n=4$ for each group. **P < 0.0I, EMS group and RADAI6-I-EM group vs Control group, RADAI6-I-EM group vs EMS group. The red arrows “ 7 ” in figures (B and D) represent tumor cell apoptosis and proliferation, respectively.

mice treated with free EM and RADA16-I-EM hydrogels was effectively inhibited (Figure 8D). In particular, the inhibition effects of RADA16-I-EM in situ hydrogels were more obvious than those of free EM, and the powerful antitumor activity of RADA16-I-EM in situ hydrogels was primarily attributed to the efficient release of EM from RADA16-I-EM hydrogels, which allowed for better antitumor effects. Strikingly, both tumor size and tumor weight decreased significantly after the Hepa1-6 tumor-bearing mice were systematically treated with the RADA16-I-EM in situ hydrogel system (Figure $8 \mathrm{E}$ and F), indicating the effective therapeutic efficacy of the RADA16-I-EM in situ hydrogel formulation in vivo.

Major of the H\&E stained sections of tumor tissues in the PBS and RADA16-I groups showed excessive cell proliferation and obvious nuclear polymorphisms. Tumor-bearing mice treated by free EM and RADA16I-EM hydrogels exhibited reduced tumor cells and enhanced levels of tumor necrosis in the H\&E-stained sections of tumor tissues; however, the RADA16-I-EM hydrogels group showed the fewest tumor cells and the highest level of tumor necrosis among all the groups (Figure 9A). Immunohistochemical analysis was performed to detect the expression of TUNEL-positive cells in tumor tissues (Figure 9B). The TUNEL assay, which was used to assess tumor apoptosis, also confirmed that treatment with the RADA16-I-EM in situ hydrogels induced more significant levels of apoptosis than that in other groups, implying the relatively high antitumor activity of the RADA16-I-EM hydrogels compared with free EM. Consistent with the results obtained from the H\&E and TUNEL staining assays, the Ki-67 staining assay also demonstrated that RADA16-I-EM hydrogel treatment significantly reduced the percentage of Ki67positive cells proliferation to a higher extent than any other group (Figure 9D). The levels of cells proliferation 


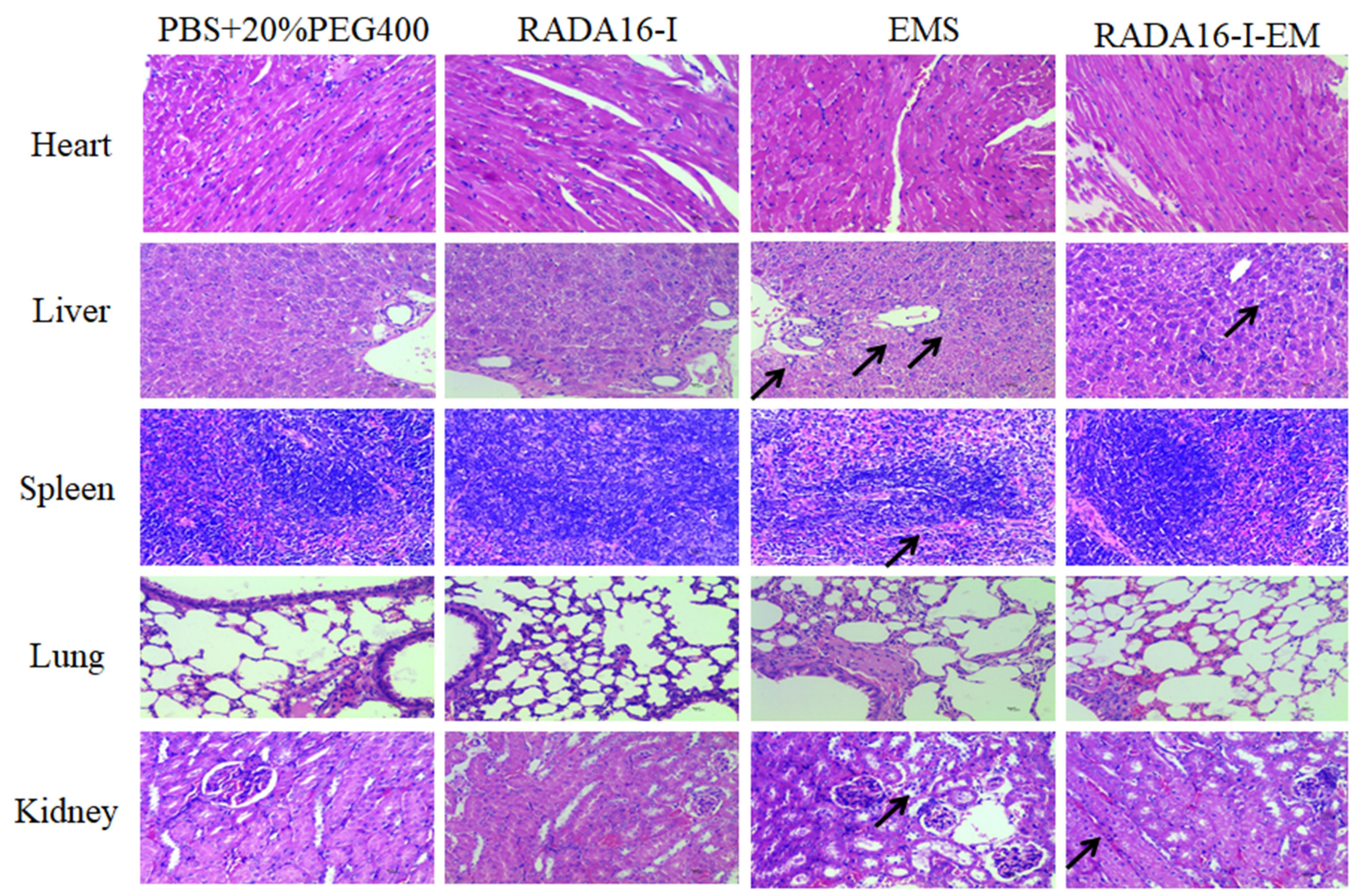

Figure 10 H\&E staining of main organs (heart, liver, spleen, lungs, and kidneys) from Hepa I-6 tumor-bearing mice on the I4th day of treatment. “ $\nearrow$ ” represents the toxic site of the organs tissue during the drug EM administration.

in tumor after treatment were also evaluated (Figure 9C and E). There was a high level of TUNEL-positive cells and lower Ki67-positive cells in tumor after treatment with EMS and RADA16-I-EM, especially in the RADA16-I-EM in situ hydrogels, with a significant statistical difference from other groups. These results together demonstrated that RADA16-I-EM in situ hydrogels could significantly improve antitumor effects. Moreover, no significant body weight loss was recorded in the mice in any group during the 14 days of treatment (Figure 8A). In addition, systemic toxicity to major organs (heart, liver, spleen, lungs, and kidneys) was investigated by H\&E staining (Figure 10), and the results strongly suggested low systemic toxicity and the minimum side effects of the RADA16-I-EM in situ hydrogel formulation.

\section{Conclusions}

EM can be effectively loaded into the suspension formed under mechanical stirring with the self- assembling peptide RADA16-I in water, and the suspension can form hydrogels in situ, in buffer solutions in vitro, and in para-/intra-tumor tissues in vivo. The RADA16-I-EM in situ hydrogels can effectively improve the proliferation-inhibiting effects on Hepa16 liver tumor cells and reduce the toxic effects on normal cells of EM in vitro. Furthermore, the RADA16-I-EM in situ hydrogels can significantly reduce the tumor growth rate and reduce the toxic side effects of EM on normal organs in vivo compared with the free EM in subcutaneously implanted murine Hepa1-6 liver tumor models, which was primarily attributed to the RADA16-I-EM hydrogels effectively delivering EM into the tumor tissue. Hence, this study demonstrated that the suspension-in situ hydrogels constructed with the self-assembling peptide RADA16-I can be used as a promising nanoplatform for stabilized hydrophobic drug administration and a localized sustained drug delivery system in biomedicine, highlighting their potential in further clinical applications. 


\section{Acknowledgments}

This work was supported by the National Natural Science Foundation of China (NO: 31460246), Beijing Nova Program (xx2018040), the Guizhou Provincial Science and Technology Foundation (NO: Qiankehe LH [2014] 7564), the Project of Special Funds for Science and Technology Cooperation in Guizhou Provinces and Zunyi City (Shengshikehe [2015] 53), Talents Training Project Fund of Zunyi City "15581 Talents Elite Project" (NO: 31460246).

\section{Disclosure}

The authors have declared no competing interests in this work.

\section{References}

1. Zhao H, Yan G, Zheng L, et al. STIM1 is a metabolic checkpoint regulating the invasion and metastasis of hepatocellular carcinoma Theranostics. 2020;10(14):6483-6499. doi:10.7150/thno.44025

2. Ho YJ, Yeh CK. Concurrent anti-vascular therapy and chemotherapy in solid tumors using drug-loaded acoustic nanodroplet vaporization. Acta Biomater. 2017;49:472-485. doi:10.1016/j.actbio.2016.11.018

3. Xiao J, Zhou J, Liang L, et al. Sensitivity of ASPP and P-gp to neoadjuvant chemotherapy combined with gene therapy in locally advanced cervical cancer. J BUON. 2019;24(3):967-974.

4. Yang Z, Dai Y, Shan L, et al. Tumour microenvironment-responsive semiconducting polymer-based self-assembly nanotheranostics. Nanoscale Horiz. 2019;4(2):426-433. doi:10.1039/C8NH00307F

5. Khaliq NU, Oh KS, Sandra FC, et al. Assembly of polymer micelles through the sol-gel transition for effective cancer therapy. $J$ Control Release. 2017;255:258-269. doi:10.1016/j.jconrel.2017.04.039

6. Wang S, Zhang F, Yu G, et al. Zwitterionic-to-cationic charge conversion polyprodrug nanomedicine for enhanced drug delivery. Theranostics. 2020;10(15):6629-6637. doi:10.7150/thno.47849

7. Xu Y, Zhai X, Su P, et al. Highly stable semiconducting polymer nanoparticles for multi-responsive chemo/photothermal combined cancer therapy. Theranostics. 2020;10(13):5966-5978. doi:10.7150/ thno. 43090

8. Zou G, Zhang X, Wang L, et al. Herb-sourced emodin inhibits angiogenesis of breast cancer by targeting VEGFA transcription. Theranostics. 2020;10(15):6839-6853. doi:10.7150/thno.43622

9. Ahn SM, Kim HN, Yu RK, et al. Emodin from polygonum multiflorum, ameliorates oxidative toxicity in HT22 cells and deficits in photothrombotic ischemia. $J$ Ethnopharmacol. 2016;188:13-20. doi:10.1016/j.jep.2016.04.058

10. Huang J, Gong W, Chen Z, et al. Emodin self-emulsifying platform ameliorates the expression of FN, ICAM- 1 and TGF- $\beta 1$ in AGEsinduced glomerular mesangial cells by promoting absorption. Eur J Pharm Sci. 2016;99:128-136. doi:10.1016/j.ejps.2016.12.012

11. Ma YS, Weng SW, Lin MW, et al. Antitumor effects of emodin on LS1034 human colon cancer cells in vitro and in vivo: roles of apoptotic cell death and LS1034 tumor xenografts model. Food Chem Toxicol. 2012;50(5):1271-1278. doi:10.1016/j.fct.2012.01.033

12. Haque E, Kamil M, Irfan S, et al. Blocking mutation independent p53 aggregation by emodin modulates autophagic cell death pathway in lung cancer. Int J Biochem Cell Biol. 2018;96:90-95. doi:10.1016/j. biocel.2018.01.014
13. Zhang L, He D, Li K, et al. Emodin targets mitochondrial cyclophilin D to induce apoptosis in HepG2 cells. Biomed Pharmacother. 2017;90:222-228. doi:10.1016/j.biopha.2017.03.046

14. Iwanowycz S, Wang J, Hodge J, et al. Emodin inhibits breast cancer growth by blocking the tumor-promoting feedforward loop between cancer cells and macrophages. Mol Cancer Ther. 2016;15 (8):1931-1942. doi:10.1158/1535-7163.MCT-15-0987

15. Lu J, Xu Y, Zhao Z, et al. Emodin suppresses proliferation, migration and invasion in ovarian cancer cells by down regulating ILK in vitro and in vivo. Oncotarget Ther. 2017;10:3579-3589. doi:10.2147/OTT.S138217

16. Tu Y, Wu Z, Tan B, et al. Emodin: its role in prostate cancer-associated inflammation (Review). Oncol Rep. 2019;42:1259-1271. doi:10.3892/ or.2019.7264

17. Park B, Yoon W, Yun J, et al. Emodin-nicotinamide (1:2) cocrystal identified by thermal screening to improve emodin solubility. Int J Pharm. 2019;557:26-35. doi:10.1016/j.ijpharm.2018.12.027

18. Fu M, Tang W, Liu JJ, et al. Combination of targeted daunorubicin liposomes and targeted emodin liposomes for treatment of invasive breast cancer. J Drug Target. 2020;28(3):245-258. doi:10.1080/ 1061186X.2019.1656725

19. Song Y, Sheng Z, Xu Y, et al. Magnetic liposomal emodin composite with enhanced killing efficiency against breast cancer. Biomater Sci. 2019;7(3):867-875. doi:10.1039/c8bm01530a

20. Yang Z, Xu H, Zhao X. Designer self-assembling peptide hydrogels to engineer 3D cell microenvironments for cell constructs formation and precise oncology remodeling in ovarian cancer. Adv Sci (Weinh). 2020;7(9):1903718. doi:10.1002/advs.201903718

21. Karavasili C, Andreadis DA, Katsamenis OL, et al. Synergistic antitumor potency of a self-assembling peptide hydrogel for the local co-delivery of doxorubicin and curcumin in the treatment of head and neck cancer. Mol Pharm. 2019;16(6):2326-2341. doi:10.1021/acs. molpharmaceut. $8 \mathrm{~b} 01221$

22. Song X, Zhang Z, Zhu J, et al. Thermoresponsive hydrogel induced by dual supramolecular assemblies and its controlled release property for enhanced anticancer drug delivery. Biomacromolecules. 2020;21 (4):1516-1527. doi:10.1021/acs.biomac.0c00077

23. Kumar S, Bajaj A. Advances in self-assembled injectable hydrogels for cancer therapy. Biomater Sci. 2020;8(8):2055-2073. doi:10.1039/ dobm00146e

24. Luo J, Wu Z, Lu Y, et al. Intraperitoneal administration of biocompatible hyaluronic acid hydrogel containing multi-chemotherapeutic agents for treatment of colorectal peritoneal carcinomatosis. Int J Biol Macromol. 2020;152:718-726. doi:10.1016/j.ijbiomac.2020.02.326

25. Vigata M, Meinert C, Pahoff S, et al. Gelatin methacryloyl hydrogels control the localized delivery of albumin-bound paclitaxel. Polymers (Basel). 2020;12(2):501-521. doi:10.3390/ polym 12020501

26. Wu C, Liu J, Zhai Z, et al. Double-crosslinked nanocomposite hydrogels for temporal control of drug dosing in combination therapy. Acta Biomater. 2020;106:278-288. doi:10.1016/j. actbio.2020.02.021

27. Peng F, Zhang W, Qiu F. Self-assembling peptides in current nanomedicine: versatile nanomaterials for drug delivery. Curr Med Chem. 2020;27(29):4855-4881. doi:10.2174/0929867326666190712154021

28. Morsi N, Ghorab D, Refai H, et al. Ketoroloac tromethamine loaded nanodispersion incorporated into thermosensitive in situ gel for prolonged ocular delivery. Int J Pharm. 2016;506:57-67. doi:10.1016/j. ijpharm.2016.04.021

29. Chu K, Chen L, Xu W, et al. Preparation of a paeonol-containing temperature-sensitive in situ gel and its preliminary efficacy on allergic rhinitis. Int J Mol Sci. 2013;14(3):6499-6515. doi:10.3390/ ijms 14036499

30. Wei W, Li H, Yin C, et al. Research progress in the application of in situ hydrogel system in tumor treatment. Drug Deliv. 2020;27 (1):460-468. doi:10.1080/10717544.2020.1739171 
31. Lammi C, Bollati C, Gelain F, et al. Enhancement of the stability and anti-DPPIV activity of hempseed hydrolysates through self-assembling peptide-based hydrogels. Front Chem. 2019;6:670. doi:10.3389/ fchem.2018.00670

32. Li X, Cao C, Wei P, et al. Self-assembly of amphiphilic peptides for recognizing high furin-expressing cancer cells. ACS Appl Mater Interfaces. 2019;11(13):12327-12334. doi:10.1021/acsami.9b01281

33. Pan A, Wang Z, Chen B, et al. Localized co-delivery of collagenase and trastuzumab by thermosensitive hydrogels for enhanced antitumor efficacy in human breast xenograft. Drug Deliv. 2018;25 (1):1495-1503. doi:10.1080/10717544.2018.1474971

34. Song Q, Zhang R, Lei L, et al. Self-assembly of succinated paclitaxel into supramolecular hydrogel for local cancer chemotherapy. $J$ Biomed Nanotechnol. 2018;14(8):1471-1476. doi:10.1166/ jbn.2018.2595

35. Capanema NSV, Mansur AAP, Carvalho SM, et al. Bioengineered carboxymethyl cellulose-doxorubicin prodrug hydrogels for topical chemotherapy of melanoma skin cancer. Carbohydr Polym. 2018;195:401-412. doi:10.1016/j.carbpol.2018.04.105

36. Lee C, Lim K, Kim SS, et al. Near infrared light-responsive heat-emitting hemoglobin hydrogels for photothermal cancer therapy. Colloids Surf Biointerfaces. 2019;176:156-166. doi:10.1016/j.colsurfb.2018.12.070

37. Javanbakht S, Namazi H. Doxorubicin loaded carboxymethyl cellulose/graphene quantum dot nanocomposite hydrogel films as a potential anticancer drug delivery system. Mater Sci Eng C-Mater Biol Appl. 2018;87:50-59. doi:10.1016/j.msec.2018.02.010

38. Han TS, Hur K, Choi B, et al. Improvement of anti-cancer drug efficacy via thermosensitive hydrogel in peritoneal carcinomatosis in gastric cancer. Oncotarget. 2017;8(65):108848-108858. doi:10.18632/oncotarget.22312

39. Pal VK, Jain R, Roy S. Tuning the supramolecular structure and function of collagen mimetic ionic complementary peptides via electrostatic interactions. Langmuir. 2020;364(4):1003-1013. doi:10.1021/acs.langmuir.9b02941

40. Shamsi F. Investigation of human cell response to covalently attached RADA16-I peptide on silicon surfaces. Colloids Surf B Biointerfaces. 2016;145:470-478. doi:10.1016/j.colsurfb.2016.05.030

41. Wu D, Zhang S, Zhao Y, et al. The effects of motif net charge and amphiphilicity on the self-assembly of functionally designer RADA16-I peptides. Biomed Mater. 2018;13(3):035011. doi:10.1088/1748-605X/aab2fd

42. Taghavi L, Aramvash A, Seyedkarimi MS, et al. Evaluation of the hemocompatibility of RADA 16-I peptide. J Biomater Appl. 2018;32 (8):1024-1031. doi:10.1177/0885328217748861
43. Liu J, Zhang L, Yang Z, et al. Controlled release of paclitaxel from a self-assembling peptide hydrogel formed in situ and antitumor study in vitro. Int $J$ Nanomedicine. 2011;6:2643-2653. doi:10.2147/IJN. S24038

44. Wei W, Meng C, Wang Y, et al. The interaction between self assembling peptides and emodin and the controlled release of emodin from in-situ hydrogel. Artif Cells Nanomed and Biotechnol. 2019;47 (1):3961-3975. doi:10.1080/21691401.2019.1673768

45. Meng C, Wei W, Wang Y, et al. Study on the interaction between self-assembling peptide and mangiferin and in vitro release of mangiferin from in-situ hydrogel. Int $J$ Nanomedicine. 2019;14:7447-7460. doi:10.2147/IJN.S208267

46. Saini A, Serrano K, Koss K, et al. Evaluation of the hemocompatibility and rapid hemostasis of (RADA)4 peptide-based hydrogels. Acta Biomater. 2016;31:71-79. doi:10.1016/j.actbio.2015.11.059

47. Mittal P, Vardhan H, Ajmal G, et al. Formulation, optimization, hemocompatibility and pharmacokinetic evaluation of PLGA nanoparticles containing paclitaxel. Drug Develop Communicat. 2019;45 (3):365-378. doi:10.1080/03639045.2018.1542706

48. Haag SL, Bernards MT. Enhanced biocompatibility of polyampholyte hydrogels. Langmuir. 2020;36(13):3292-3299. doi:10.1021/acs. langmuir.0c00114

49. Naahidi S, Wang Y, Zhang M, et al. Evaluation of biocompatibility of the AC8 peptide and its potential use as a drug carrier. Mol Pharm. 2014;11(10):3409-3420. doi:10.1021/mp5001185

50. Zhang F, Lu G, Wen X, et al. Magnetic nanoparticles coated with polyphenols for spatio-temporally controlled cancer photothermal/ immunotherapy. J Control Release. 2020;326:131-139. doi:10.1016/ j.jconrel.2020.06.015

51. Cheng Y, Jiao X, Fan W, et al. Controllable synthesis of versatile mesoporous organosilica nanoparticles as precision cancer theranostics. Biomaterials. 2020;256:120191. doi:10.1016/j. biomaterials.2020.120191

52. Ma Q, Ding Y, Wu Z, et al. Antitumor effects of emodin in Caco-2 human colon carcinoma cells are mediated via apoptosis, cell cycle arrest and downregulation of $\mathrm{PI} 3 \mathrm{~K} / \mathrm{AKT}$ signalling pathway. J BUON. 2018;23(3):587-591.

53. Trybus W, Król T, Trybus E, et al. Emodin induces death in human cervical cancer cells through mitotic catastrophe. Anticancer Res. 2019;39(2):679-686. doi:10.21873/anticanres.13163
International Journal of Nanomedicine

\section{Publish your work in this journal}

The International Journal of Nanomedicine is an international, peerreviewed journal focusing on the application of nanotechnology in diagnostics, therapeutics, and drug delivery systems throughout the biomedical field. This journal is indexed on PubMed Central, MedLine, CAS, SciSearch ${ }^{\mathbb{B}}$, Current Contents ${ }^{\mathbb{B}} /$ Clinical Medicine, $^{2}$
Journal Citation Reports/Science Edition, EMBase, Scopus and the Elsevier Bibliographic databases. The manuscript management system is completely online and includes a very quick and fair peer-review system, which is all easy to use. Visit http://www.dovepress.com/ testimonials.php to read real quotes from published authors. 